\title{
Rejoinder to "Response to 'Critique of "A Prospectively Studied Near-Death Experience with Corroborated Out- of-Body Perceptions and Unexplained Healing","
}

\author{
Michael J. Rush, M.A., P.G.Dip. \\ Alister Hardy Society for the Study of Spiritual Experience
}

I would like to thank Penny Sartori for responding to my criticisms and giving me the opportunity to engage in such an enjoyable and interesting debate. She provides many clarifications and additional pieces of information that address many of the individual criticisms I raised in my critique. It is inevitable that much of this detail cannot be mentioned in a single journal article due to the need to focus on the essentials. Sartori's Ph.D. study is an admirable piece of work, which a single article cannot convey.

In her response Sartori provided a number of clarifications and additional information, which I summarize as follows. She confirmed that she gave patients the opportunity to provide an open-ended response prior to using the NDE Scale and that the images used in the final study bore no resemblance to the hypothetical images suggested in the pilot. Both of these clarifications reduce the possibility that information, which could have subsequently influenced the patient's responses, was inadvertently leaked. Sartori has also drawn attention to the non-verbal information that cannot be included in an interview transcript but is nevertheless still valuable supportive evidence, such as gestures and facial expressions. Sartori also clarified the nature

Michael J. Rush, M.A., P.G.Dip., is Vice Chair of The Alister Hardy Society for the Study of Spiritual Experience in Lampeter, Wales. The opinions expressed in this article are those of the author alone. Correspondence regarding this article should be sent to Mike Rush at email: mikerush@virginmedia.com. 
of the ITU environment for those of us who are not familiar with it, which can indeed put a different perspective on the understanding of the situation she was describing. She has also clarified the timing of events in relation to the period of the patient's unconsciousness, in particular with respect to the apparent observations of the consultant anesthetist and the worried physiotherapist.

\section{Clarifications of My Criticisms}

Whereas I don't wish to overly extend the debate, there are a few points of my critique that I would like to clarify. Firstly, the focus of my critique was Sartori's 2006 paper, not her Ph.D. thesis. I only referred to the Ph.D. thesis in order to clarify my understanding of the paper. Sartori's response has drawn attention to parts of her thesis relevant to my critique. In fact, some of my initial criticisms were answered by the thesis and never made it into the critique. However, although in her thesis she discussed the unexplained healing and effects of drug administration, the main focus of her 2006 paper seems to have been on the veridical aspects of the case study, so these were the focus of my criticisms.

Secondly, the cognitive mechanisms and phenomena I suggested operate outside of awareness; I never intended to imply that patients or medical staff intentionally passed on information. Sartori commented that the medical staff is highly trained in their observational and record keeping skills. This I do not doubt! However, even police officers and others trained in observation skills have been shown to perform no better than anyone else in this respect (Loftus, 1979, pp. 163-170). Thirdly, the main argument of my critique was to suggest that these psychological mechanisms are effectively impossible to rule out in such a naturalistic environment. Fourthly, my suggestion of using a blind panel to judge accuracy of reported observations was with respect to the original target images, not the circumstantial observations that patients may make. I agree with her that the latter would be unworkable. Fifthly, it is important to point out that expectation effects do not rule out the possibility of surprise. I drew a parallel with set and setting in drug research wherein there may well be expectation that a given drug will have an effect - for example, a placebo or psychedelicbut the particular form that effect takes may be totally unexpected. My point was that set and setting are applicable to any experience, not just drug induced ones. Finally, in my discussion about 'Truth versus 
Meaning' I was not criticizing Sartori's comments about the personal meaning of NDEs but was agreeing with them. I think that the more important aspect of NDEs is the meaning and effect they have for individual experiencers rather than their evidential value for ontological arguments.

\section{Two Remaining Problems}

Although Sartori's response addressed many of my individual criticisms, it seems to me that there remain two major problems with the kind of research she conducted. The first is that of the difficulty, if not sheer impossibility, of avoiding confounding factors in the naturalistic setting of the ITU ward. Sartori herself seemed to agree with this point in her response to my critique. I believe that the psychological phenomena I suggested-cryptomnesia, set and setting, expectation, suggestion, implicit memory, false memories, and possibly other nonconscious processes-could account for the patients' apparent observations while in an unconscious state, and are, therefore, examples of such confounding factors. Sartori argued that my critique simply restated some of the factors she had already acknowledged as problematic. However, my intent was to highlight these in relation to the psychological phenomena that could provide an alternative explanation for the apparently veridical observations during unconsciousness. After reading Sartori's 2006 paper and her Ph.D. thesis (Sartori, 2008), I felt that the 'mind-models' explanation required a more comprehensive exploration. In my view these confounding factors have not been, indeed probably could not be, adequately controlled for in the ITU environment. Although Sartori went to admirable lengths to minimise these factors, I still have serious doubts about the level of evidence studies such as these can provide.

I think that the second major problem with this kind of research is that of reducing subjectivity when measuring accuracy. I suggested that the methodology could have been further strengthened by using a double-blind technique for the target images. I note that in her response Sartori appears to have dropped the first of her three 'accurate observations'. It is the remaining two that, while appearing to be accurate, could conceivably be accounted for by the known phenomena I put forward. For example, it is not necessary for the patient to have actually seen the anaesthetist poking her head around the curtain at that time; simply overhearing a comment to that effect afterwards 
may have been enough to elicit a false memory of that incident. Memory has been shown to be reconstructive in nature and easily influenced by both direct and indirect; suggestion.

I think that much in our exchange emphasizes the differing perspectives and biases of both the researcher and the critiquer. Sartori stated, "Thus, although it cannot be entirely ruled out that one or more colleagues overheard a research interview, I consider the likelihood next to impossible," to which my response would be "Thus, although it cannot be entirely ruled out that a veridical OBE occurred, I consider the likelihood less probable than an explanation in terms of known psychological processes." Given the confounding factors and ambiguity of ascertaining accuracy, I suspect this difference in our perspectives may leave us at something of an impasse.

A potential weakness with my own critique, that I am uncomfortably aware of, is that the psychological phenomena that I propose as alternative known explanatory mechanisms for observations made during unconsciousness may not be applicable in this particular case. For example, I gave the example of blindsight to illustrate a welldocumented example of non-conscious processing (Weiskrantz, 1986). However, as far as I'm aware, the patient in Sartori's case study was not blind. Blindsight itself may not, therefore, be a realistic alternative explanation in this case, and an analogous phenomenon in sighted people would have to be sought for instead.

\section{Conclusion}

In my opinion, the difficulty of discounting these known psychological mechanisms as alternative explanations means that Sartori's conclusion to her 2006 paper is overstated. I cannot agree that "There are many aspects of this case for which our current brain/mind models cannot provide an adequate explanation . .." or, therefore, that "Although this is only one case, it strengthens the cumulative experience derived from many other individual cases . . . that suggest that our current models of consciousness must expand in order to provide an adequate explanation of NDEs" (Sartori, 2006, p. 83).

I certainly accept that for the NDEr, and perhaps for some of the medical staff involved, the experience and the subsequent account of it are highly convincing. However, skeptical readers of an article in a journal do not have the benefit of this experiential proximity and must, therefore, base their conclusions on the facts as presented. I also stated, perhaps too provocatively, that the study had "failed." What 
I meant by this statement was that no patients reported seeing the target images. It was therefore not possible to conclude whether the observations were due to a 'mind model' or to some other anomalous phenomenon. Nevertheless, Sartori seems to have presented the circumstantial observations as evidence and seems to have come to the conclusion that might have been warranted had numerous correct target observations, in fact, been made.

Sartori denied that she is making an "extraordinary claim" in her conclusion. Perhaps this is a subjective point, but to my mind a conclusion that calls for "expanding our models" on the basis of the evidence just presented requires substantial empirical justification and the absence of alternative explanatory factors. However, perhaps I had in mind Sartori's comments from her Ph.D. thesis that reports from OBErs lend "further support to the possibility of consciousness existing apart from the brain" (Sartori, 2008, p. 274) and that the cumulative effect of other cases from her Ph.D. research "totally contradicts the current scientific worldview. If these experiences can't be explained away," said Sartori, "then we have no option but to seek alternatives to our current scientific theories" (Sartori, 2008, p. 310).

In conclusion, Sartori has certainly provided additional information and clarification of many points, for which I am grateful. However, for me, the value and meaning of an NDE for the experiencer remains far more important than whether or not ND OBEs provide veridical observations during unconsciousness.

\section{References}

Loftus, E. (1979). Eyewitness testimony. Cambridge, MA: Harvard University Press.

Sartori, P., Badham, P., \& Fenwick, P. (2006). A prospectively studied neardeath experience with corroborated out-of-body perceptions and unexplained healing, Journal of Near-Death Studies, 25(2), 69-84.

Sartori, P. (2008). The NDEs of hospitalized intensive care patients: A five year clinical study. Lampeter, Wales: Edwin Mellen Press.

Weiskrantz, L. (1986). Blindsight: A case study spanning 35 years and new developments. Oxford, England: Oxford University Press. 